\title{
Cascade control of BLDC motor drive using MOMI tuning method
}

\author{
${ }^{* 1}$ Prema kumar Navuri, ${ }^{2}$ Manoj Kumar Merugumalla \\ ${ }^{1,2}$ Department of Electrical Engineering, Andhra University, Visakhapatnam, India \\ Email:prema.ee@auvsp.edu.in, mkla2009@gmail.com
}

\section{Received: $10^{\text {th }}$ Feb 2018, Accepted: $15^{\text {th }}$ March 2018, Published: $30^{\text {th }}$ April 2018}

\begin{abstract}
This paper presents a new design concept for cascade control of brushless direct current (BLDC) motor drive. Cascade controllers are designed for definite separation of loops. This separation allows independent design of controllers with minimum interaction among loops. The resultant structure with inner loop and outer loop is a robust structure. Magnitude Optimum Multiple Integration (MOMI) tuning method is proposed to design the PID controllers used in inner and outer loops. This method provides a fast and non-oscillatory closedloop response for motor drives. The aim of the proposed method is to determine optimal Proportional-Integral-Derivative gains of the controller so as to force the rotor to follow the reference speed without any oscillations with zero steady-state error. MOMI method proceeds by determining the open-loop process gain to calculate the moments (areas), from which controller parameters can be calculated. The MATLAB/SIMULINK is used for simulation of the drive system. Several simulation tests performed to investigate the robustness of the controller and is justified by the simulation of BLDC drive under setpoint changes, input disturbance and load disturbances.
\end{abstract}

Keywords: BLDC motor; MOMI; PID controller; Trapezoidal back emf; Cascade control

\section{Introduction}

BLDC motor has wide range of applications because of its advantages such as high efficiency, flat speedtorque characteristics, and high speed range, smaller in size and lighter, longer life, low noise and good dynamic response when compared against brushed direct current motor. Both, DC brushed and brushless motors contain a combination of Permanent magnet and electromagnetic fields, which produce torque resulting in motion. In a brushless DC motor, the rotor consists of magnets and stator contains the windings and no brushes present as name suggests. Commutation is implemented electronically in brushless motors using semiconductor switches to change current in the windings based on position of rotor [1]. The BLDC motor is an equivalent reversed DC commutator motor, as its magnet rotates while the conductors remain stationary, this facilitates the external or internal position sensors in BLDC motors to sense the actual rotor position. The rotor position position can also be sensed by measuring the changes in back emf, which is sensorless control [2]. As sensors cannot be used in all applications, the back emf method of commutation is used to simplify the motor construction and can reduce the cost of the motor.

This paper provides an approach for application of PID controllers in cascade control of BLDC motor drive system. The cascade control configuration consists of two loops. The inner loop is called current control loop (secondary loop) and outer loop is called speed control loop (primary loop). Each loop is associated with its PID controller. Therefore, it is complicated design than that of single loop controller. A new method, Magnitude optimum multiple integration (MOMI) is proposed for tuning two controllers in cascade control system.

\section{Bldc Motor Model}

The stator windings of BLDC motor should be energized in a sequence to rotate the motor, to understand which winding to be energized following the energizing sequence, It is important to know the position of rotor. Rotor position is sensed by measuring the changes in the back emf. With this type of commutation, Hall sensors can be eliminated which simplifies the construction of motor and reduces the cost as well [3][4].

$$
\begin{gathered}
V_{a n}=R_{a} i_{a}+\frac{d}{d t}\left(L_{a a} i_{a}+L_{b a} i_{b}+L_{c a} i_{c}+\right. \\
\left.e_{a}\right) \\
V_{b n}=R_{b} i_{b}+\frac{d}{d t}\left(L_{a b} i_{a}+L_{b b} i_{b}+L_{c b} i_{c}+\right. \\
\left.e_{b}\right) \\
V_{c n}=R_{c} i_{c}+\frac{d}{d t}\left(L_{a c} i_{a}+L_{b c} i_{b}+L_{c c} i_{c}+\right.
\end{gathered}
$$

$\left.e_{c}\right)$

Assume,

$$
\begin{gathered}
R_{a}=R_{b}=R_{c}=R \\
L_{a a}=L_{b b}=L_{c c}=L_{s} \\
L_{a b}=L_{b a}=L_{c a}=L_{a c}=L_{b c}=L_{c b}=M
\end{gathered}
$$

In the matrix form,

$$
\begin{gathered}
{\left[\begin{array}{l}
V_{a n} \\
V_{b n} \\
V_{c n}
\end{array}\right]=\left[\begin{array}{lll}
R & 0 & 0 \\
0 & R & 0 \\
0 & 0 & R
\end{array}\right]\left[\begin{array}{l}
i_{a} \\
i_{b} \\
i_{c}
\end{array}\right]+\left[\begin{array}{lll}
L_{s} & M & M \\
M & L_{s} & M \\
M & M & L_{s}
\end{array}\right] \frac{d}{d t}\left[\begin{array}{l}
i_{a} \\
i_{b} \\
i_{c}
\end{array}\right]+} \\
{\left[\begin{array}{l}
e_{a} \\
e_{b} \\
e_{c}
\end{array}\right]}
\end{gathered}
$$


Since $i_{a}+i_{b}+i_{c}=0$ and with $L_{s}-M=L$

$$
\left[\begin{array}{l}
V_{a n} \\
V_{b n} \\
V_{c n}
\end{array}\right]=\left[\begin{array}{lll}
R & 0 & 0 \\
0 & R & 0 \\
0 & 0 & R
\end{array}\right]\left[\begin{array}{c}
i_{a} \\
i_{b} \\
i_{c}
\end{array}\right]+\left[\begin{array}{lll}
L & 0 & 0 \\
0 & L & 0 \\
0 & 0 & L
\end{array}\right] \frac{d}{d t}\left[\begin{array}{c}
i_{a} \\
i_{b} \\
i_{c}
\end{array}\right]+\left[\begin{array}{c}
e_{a} \\
e_{b} \\
e_{c}
\end{array}\right]
$$

where

$R$ : Stator resistance per phase, assumed to be equal for all phases

$L s$ : Stator inductance per phase, assumed to be equal for all phases.

$M$ : Mutual inductance between the phases.

ia $, i b, i c:$ Stator currents/phase.

The instantaneous induced emfs can be written as given in equation

$$
\begin{array}{r}
e_{a}=f_{a}\left(\theta_{r}\right) \lambda_{p} \omega_{m} \\
e_{b}=f_{b}\left(\theta_{r}\right) \lambda_{p} \omega_{m} \\
e_{c}=f_{c}\left(\theta_{r}\right) \lambda_{p} \omega_{m}
\end{array}
$$

where, $\omega_{\mathrm{m}}$ is the rotor mechanical speed and $\theta_{r}$ is the rotor electrical position.

The torque equation is given as

$$
T_{e}=\lambda_{p}\left[f_{a}\left(\theta_{r}\right) i_{a}+f_{b}\left(\theta_{r}\right) i_{b}+f_{c}\left(\theta_{r}\right) i_{c}\right.
$$

The equation of motion of system is

$$
\begin{aligned}
& T_{e}=\mathrm{J} \frac{\mathrm{d} \omega}{\mathrm{dt}}+B \omega_{m}+T_{l} \\
& J \frac{d \omega_{m}}{d t}=\frac{1}{J}\left[T_{e}-T_{l}-B . \omega_{m}\right] \\
& \frac{d \theta_{r}}{d t}=\frac{P}{2} \omega_{m}
\end{aligned}
$$

where, $P$ is the number of rotor poles. The state variable $\left(\theta_{\mathrm{r}}\right)$, rotor position, is required to have the function $f_{a}\left(\theta_{r}\right)$ which is given as the trapezoidal function:

\section{Closed loop control of Bldc motor Drive}

Figure 1 represents closed loop control of BLDC motor drive. As seen in figure there are two loops, the outer loop is called speed control loop and inner loop is current control loop. The actual speed of the motor is compared with reference value, the error is applied to the speed controller. The speed controller generates reference command value $i_{\text {ref* }}$ which is compared with position of rotor, from which, in turn, reference phase currents are generated. The phase currents are compared with reference currents, difference is applied to hysteresis current controller from which, in turn switching functions are generated for three-phase voltage source inverter (VSI). The BLDC motor is supplied by inverter output voltages Van, Vbn, Vcn [4].

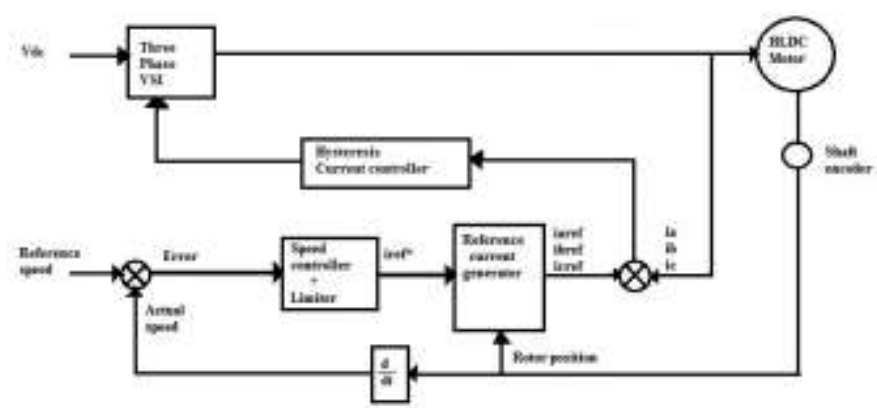

Figure 1. Closed loop control of BLDC drive

\section{Magnitude Optimum Multiple Integration tuning method}

A Magnitude optimum multiple integration tuning method is of tuning PID controller furnishes nonoscillatory closed-loop response for a huge class of process models. This method calculate controller parameter from identified model of the process. The tuning procedure for the PID controller is given for those processes which can be approximated by the following transfer function:

$$
G_{P}(s)=K_{p r} \frac{1+b_{1} s+b_{2} s^{2}+\cdots+b_{m} s^{m}}{1+a_{1} s+a_{2} s^{2}+\cdots+a_{n} s^{n}}
$$

$$
\begin{array}{cc}
f_{a}\left(\theta_{r}\right)=1 & 0<\theta_{r}<\frac{\pi}{3} \\
f_{a}\left(\theta_{r}\right)=\left(\frac{\pi}{2}-\theta_{r}\right) * \frac{6}{\pi} & \frac{\pi}{3}<\theta_{r}<\frac{2 \pi}{3} \\
f_{a}\left(\theta_{r}\right)=-1 & \frac{2 \pi}{3}<\theta_{r}<\pi \\
f_{a}\left(\theta_{r}\right)=-1 & \pi<\theta_{r}<\frac{4 \pi}{3} \\
f_{a}\left(\theta_{r}\right)=\left(\theta_{r}-3 * \pi / 2\right) * \frac{6}{\pi} & \frac{4 \pi}{3}<\theta_{r}<\frac{5 \pi}{3} \\
f_{a}\left(\theta_{r}\right)=1 & \frac{5 \pi}{3}<\theta_{r}<2 \pi
\end{array}
$$

The induced emfs are result of derivatives of flux linkages, which are continuous functions. The phase voltage equations of BLDC motor are identical to armature voltage equation of DC motor. and $a_{1}$ to $a_{n}$ and $b_{1}$ to $b_{m}$ are the corresponding parameters $(m \leq n)$ of the process transfer function, where ' $n$ ' can be an arbitrary positive integer value. The direct identification of $K_{p r}, a_{1}$ to $a_{n}, b_{1}$ to $b_{m}$ is compound and arduous, to overcome this, MOMI method uses the concept 'moments(areas)' which can be expressed by integrating the process open-loop step response after applying the step-change (dU) at the process input at $\mathrm{t}=0$.The graphical representation of moment (area) is shown in figure 4 , where $\mathrm{y}_{0}$ and $\mathrm{u}_{0}$ represents scaled process output and process input time respectively. 
The process transfer function can be expressed as areas by using the following infinite-order expression:

$$
G_{P}(s)=A_{0}-A_{1} s+A_{2} s^{2}-A_{3} s^{3}
$$

where parameters $A_{i}(i=0,1,2, \ldots)$ represent timeweighted integrals of the process response. The moments are obtained by calculating unvarying integrals of the process output and input signals during change in the process steady-state. Therefore, in practice the process can be easily parameterised by the moments. The moments $A_{1}$ to $\mathrm{A}_{5}$ can also be calculated directly from the process transfer function after determination of process steady-state gain $\mathrm{Kpr}$ from process output [6]-[9].

The process steady-state gain is calculated from the process output as

$$
K_{p r}=\frac{\left(y_{1}-y_{0}\right)}{d U}=A_{0}
$$

and by using $\mathrm{Kpr}$, the areas $\mathrm{A}_{1}$ to $\mathrm{A}_{5}$ can be calculated as :

$$
\begin{gathered}
A_{1}=K_{p r}\left(a_{1}-b_{1}\right) \\
A_{2}=K_{p r}\left(b_{2}-a_{2}\right)+\left(A_{1} a_{1}\right) \\
A_{3}=K_{p r}\left(a_{3}-b_{3}\right)+\left(A_{2} a_{1}\right)-\left(A_{1} a_{2}\right) \\
A_{4}=K_{p r}\left(b_{4}-a_{4}\right)+\left(A_{3} a_{1}\right)-\left(A_{2} a_{2}\right)+\left(A_{1} a_{3}\right) \\
A_{5}=K_{p r}\left(a_{5}-b_{5}\right)+\left(A_{4} a_{1}\right)-\left(A_{3} a_{2}\right)+\left(A_{2} a_{3}\right) \\
-\left(A_{1} a_{4}\right)
\end{gathered}
$$

By using areas $A_{1}$ to $A_{5}$, the PID controller parameters can be calculated as :

$$
\begin{array}{cc}
T_{d}=\left(A_{3} A_{4}-A_{2} A_{5}\right) /\left(A_{3} A_{3}-A_{1} A_{5}\right) & (20) \\
K_{p}=A_{3} / 2\left(A_{1} A_{2}-A_{3} K_{p r}-T_{d} A_{1}^{2}\right) & (21) \\
T_{i}=\left(A_{3}\right) /\left(A_{2}-T_{d} A_{1}\right) & {\left[\begin{array}{c}
K_{i} \\
K_{p} \\
K_{d}
\end{array}\right]=} \\
\text { inv }\left[\begin{array}{ccc}
-A_{1} & A_{0} & 0 \\
-A_{3} & A_{2} & -A_{1}-A_{0} \\
-A_{5} & A_{4} & -A_{3}-A_{2}-A_{1}-A_{0}
\end{array}\right] \times\left[\begin{array}{c}
0.5 \\
0 \\
0
\end{array}\right]
\end{array}
$$

\section{CASCADE CONTROLLER DESIGN BY MOMI TUNING METHOD}

The most popular structures for the process control is cascade control, it can be applied when process can be split into two or more parts [11]. The three parameters of PID controller $\mathrm{Kp}, \mathrm{Ki}, \mathrm{Kd}$, has to be tuned so that to obtain desired performance from the drive [12].This type of control can be used for the reduction of current and speed error in motor drives [13].The design of overall drive system involves tuning of inner and outer loop PID controllers [14]. The matlab/simulink model of cascaded BLDC drive is shown in figure 2 . The overall BLDC drive process $G(s)=G_{1}(s) G_{2}(s)$ is split into $G_{1}(s)$ and $\mathrm{G}_{2}$ (s) as:

The inner loop process (inverter and BLDC motor) transfer function is

$$
\begin{gathered}
G_{2}(s)=\frac{0.02538 s+2.08}{1.55 e^{-10} s^{3}+6.378 e^{-6} s^{2}+0.006615 s+1} \\
G_{1}(s)=\frac{2.45}{0.012 s+1}
\end{gathered}
$$

From transfer function $\mathrm{a}_{0}=1, \mathrm{a}_{1}=0.006615$, $\mathrm{a}_{2}=6.378 * 10^{-6}, \quad \mathrm{a}_{3}=1.55^{*} 10^{-10}, \quad \mathrm{~b}_{0}=2.08$, $\mathrm{b}_{1}=0.02538$.

The outer loop process (load) transfer function is

From transfer function $\mathrm{a}_{0}=1, \mathrm{a}_{1}=0.012, \mathrm{~b}_{0}=2.45$

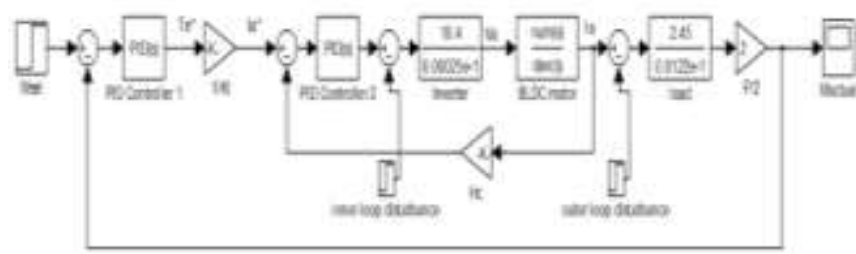

Figure 2. Matlab/simulink model of BLDC motor drive

A. Inner and outer loop controller tuning

The open-loop process input and output of process $\mathrm{G}_{2}(\mathrm{~s})$ and $\mathrm{G}_{1}(\mathrm{~s})$ is shown in figure 3 and figure 4 respectively, from which steady-state process gain $\mathrm{Kpr}$ is obtained. With known value of process gain, the areas $A_{1}$ to $A_{5}$ are calculated using equations (15) - (19). With these areas, PID controller parameters are calculated using equation (23) .The calculated areas and controller parameters for the inner loop are presented in table 1 .

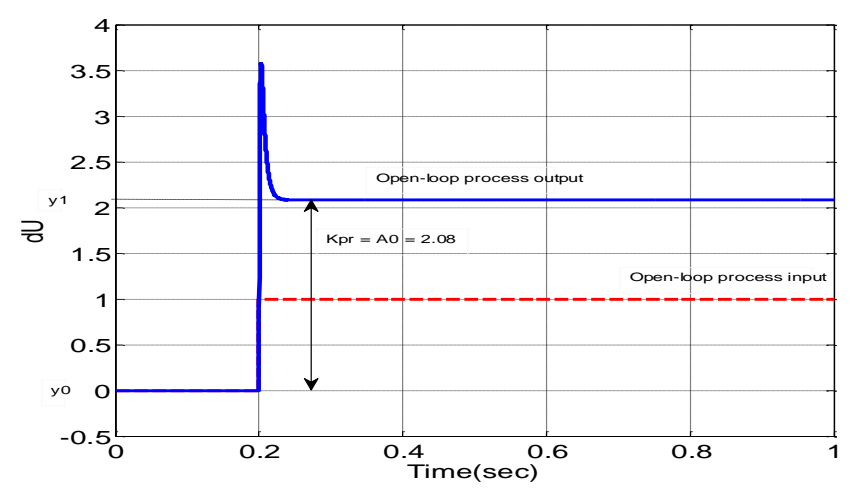

Figure 3. Open-loop process input and output of inner-loop 
Table 1. Calculated areas and Controller PARAMETERS OF INNER LOO

\begin{tabular}{|l|c|c|c|c|c|}
\hline \multicolumn{7}{|c|}{ Moments(Areas) } \\
\hline $\mathrm{A}_{0}=\mathrm{K}_{\mathrm{Pr}}$ & $\mathrm{A}_{1}$ & $\mathrm{~A}_{2}$ & $\mathrm{~A}_{3}$ & $\mathrm{~A}_{4}$ & $\mathrm{~A}_{5}$ \\
\hline 2.08 & -0.039 & $-2.7 * 10^{-4}$ & $-1.5^{*} 10^{-6}$ & $-8.50 * 10^{-9}$ & $-4.64 * 10^{-6}$ \\
\hline \multicolumn{6}{|c|}{ PID controller parameters } \\
\hline $\mathrm{K}_{\mathrm{I}}$ & $\mathrm{K}_{\mathrm{P}}$ & $\mathrm{K}_{\mathrm{D}}$ & $\mathrm{T}_{\mathrm{D}}$ & $\mathrm{T}_{\mathrm{I}}$ \\
\hline 9.8270 & 0.0560 & 0 & $9.432^{*} 10^{-4}$ & 0.0066 \\
\hline
\end{tabular}

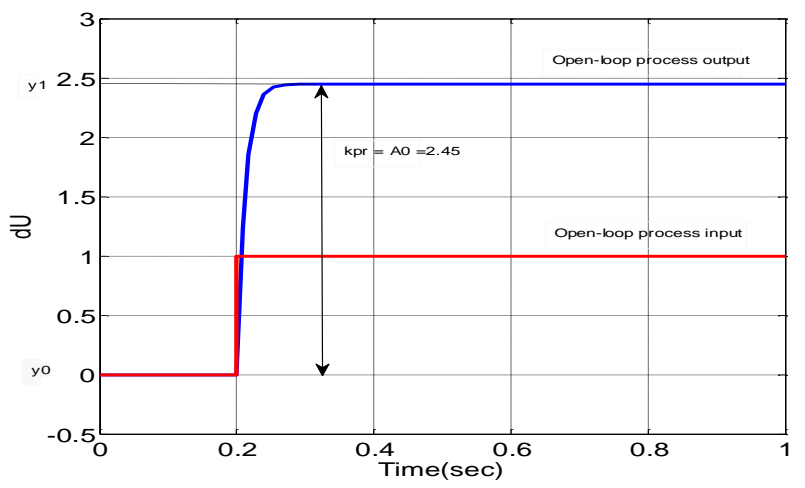

Figure 4.Open-loop process input and output of outer loop

TABle 2. CALCULATED AREAS AND CONTROLlER PARAMETERS

\begin{tabular}{|c|c|c|c|c|c|}
\hline \multicolumn{7}{|c|}{ Moments(Areas) } \\
\hline $\begin{array}{c}\mathrm{A}_{0}=\mathrm{K}_{\mathrm{P}} \\
\mathrm{R}\end{array}$ & $\mathrm{A}_{1}$ & $\mathrm{~A}_{2}$ & $\mathrm{~A}_{3}$ & $\mathrm{~A}_{4}$ & $\mathrm{~A}_{5}$ \\
\hline 2.45 & 0.0294 & $\begin{array}{c}3.52^{*} 10^{-} \\
4\end{array}$ & $\begin{array}{c}4.23 * 10^{-} \\
6\end{array}$ & $\begin{array}{c}5.0803 * 10^{-} \\
8\end{array}$ & $\begin{array}{c}6.09^{*} 10^{-} \\
10\end{array}$ \\
\hline \multicolumn{7}{|c|}{ PID controller parameters } & $\mathrm{T}_{\mathrm{I}}$ \\
\hline $\mathrm{K}_{\mathrm{I}}$ & $\mathrm{K}_{\mathrm{P}}$ & $\mathrm{K}_{\mathrm{D}}$ & $\mathrm{T}_{\mathrm{D}}$ & 0.0120 \\
\hline 1.1068 & 0.0133 & 0 & 0 & \\
\hline
\end{tabular}

\section{Results and Discussion}

In the cascade model of BLDC drive given above, the set-speed(reference speed) is taken as $\omega_{\text {ref }}=73.3$ $\mathrm{rad} / \mathrm{sec}$.

\section{A. Analysis of motor drive without disturbance:}

The speed response of the drive is shown in figure $5(a)$, it can be seen that speed response is excellent without any oscillations and steady state error. The current error from the inner-loop is shown in figure 5(b). The set-point tracking (reference speed) is shown in figure 5(c), it can be seen that tracking performance is excellent with the proposed control strategy. The speed error from the outer-loop is shown in figure $5(d)$.

\section{B. Analysis of motor drive with inner loop disturbance :}

The speed response is shown in figure 6(a), it can be seen that actual speed recovered to desired speed in very less time under the disturbance in the innerloop. The response of reference current under disturbance in inner-loop is shown in figure 6(b). The current error under disturbance and the set-point (reference speed) tracking under disturbance in inner-loop are shown in figures 6(c) and 6(d) respectively.

C. Analysis of motor drive with in outer loop disturbance :

The speed response with the proposed cascade control strategy under the disturbance in the outerloop is shown in figure 7(a), it can be seen that speed recovered without any overshoot in less time. The reference current change under the disturbance in the outer loop is shown in figure 7(b). The current error of the inner-loop under the disturbance in the outer loop is shown in figure 7(c).The set-point (reference speed) tracking under outer loop disturbance is shown in figure 7(d), it can be seen that performance is good even under the disturbance and sudden changes in the reference speed.

D. Analysis of motor drive with different values of $K_{p}, T_{i}, T_{d}$ :

Dynamic responses of speed under both inner loop and outer loop disturbances and with different values of $\mathrm{Kp}, \mathrm{Ti}, \mathrm{Td}$ without disturbance in the proposed cascade control system are shown in figure $8(a)-8(c)$ respectively. The response with different values of $\mathrm{Kp}$ from 0.001 to 0.01 is shown in figure $8(\mathrm{a})$, it can be seen that with increase in Kp value overshoot increases. The response with different values of $T_{i}$ from 0.01 to 0.1 is shown in figure $8(b)$, it can be seen that with increase in $T_{i}$ rise time and settling time increases. The response with different values of $T_{d}$ from 0.001 to 0.01 is shown in figure $8(\mathrm{c})$, it can be seen that oscillations increases with decrease in $T_{d}$ value.

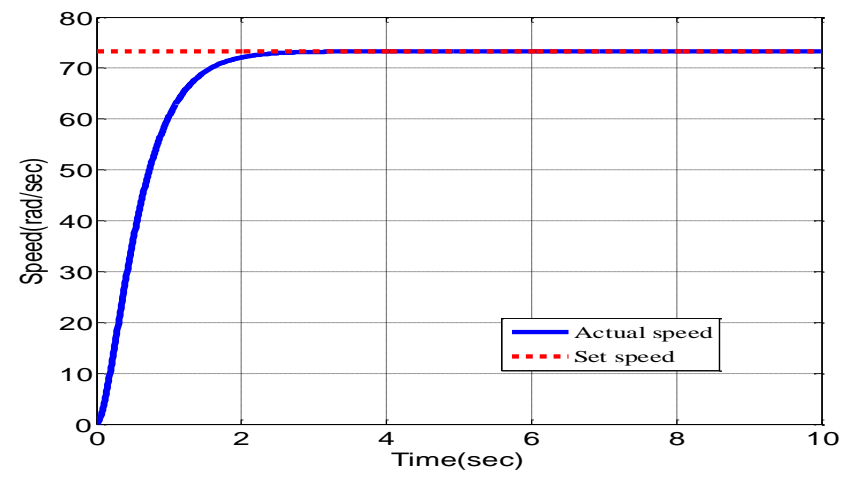

Figure 5(a)

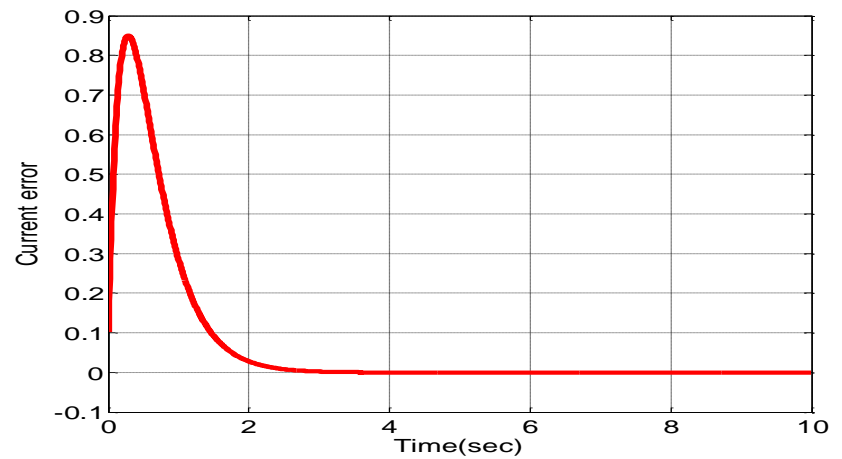


Figure 5(b)

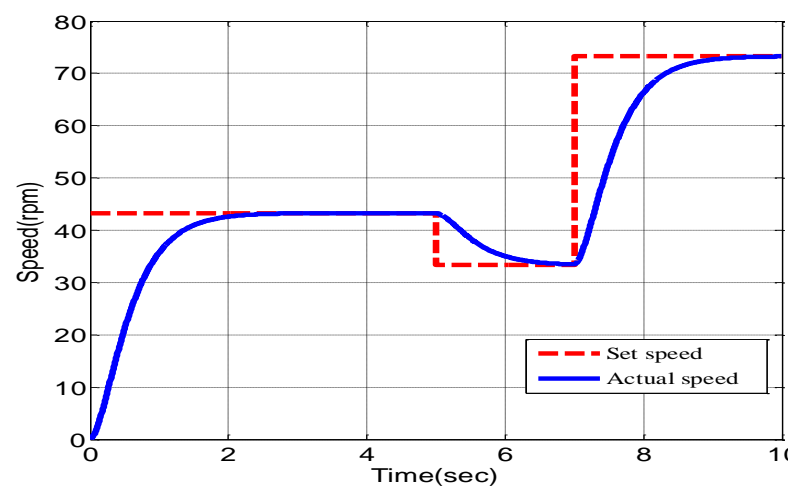

Figure 5(c)

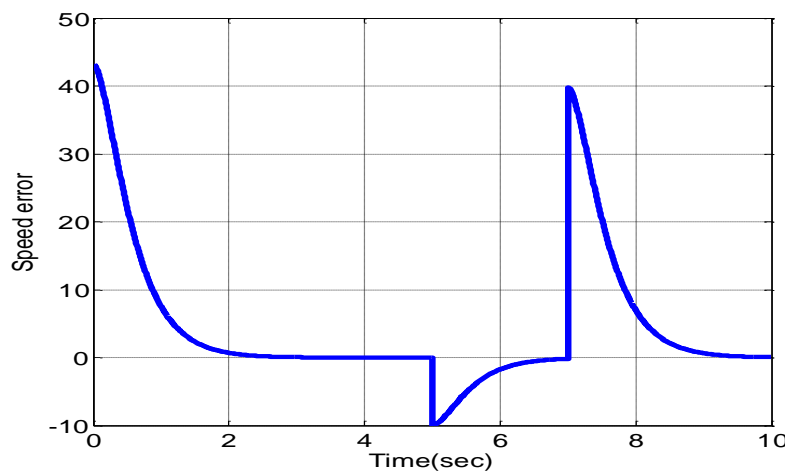

Figure 5(d)

Dynamic responses of speed, current loop error, set-point tracking and speed loop error with the proposed cascade control system are shown in figure 5 (a) -5 (d) respectively.

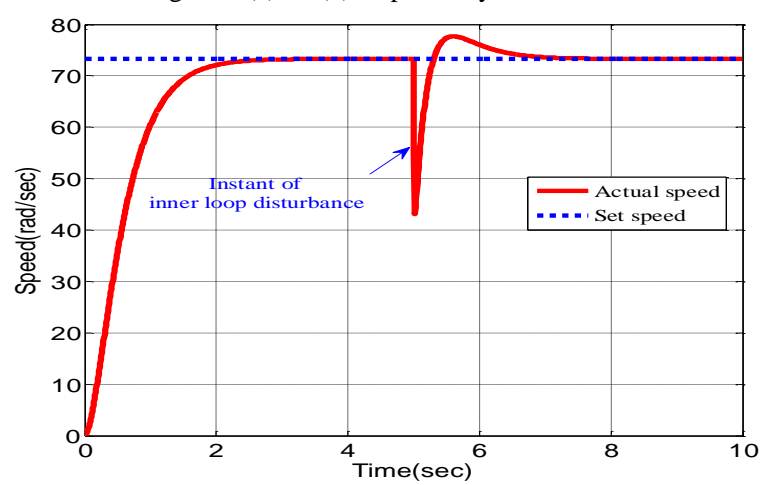

Figure 6(a)

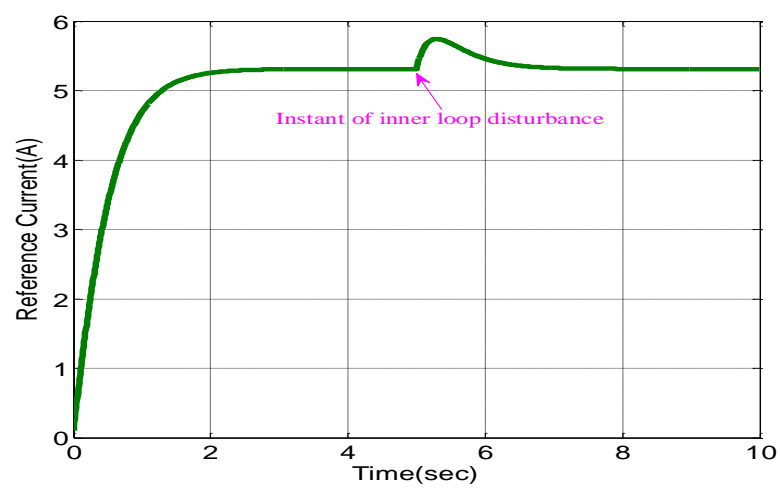

Figure 6(b)

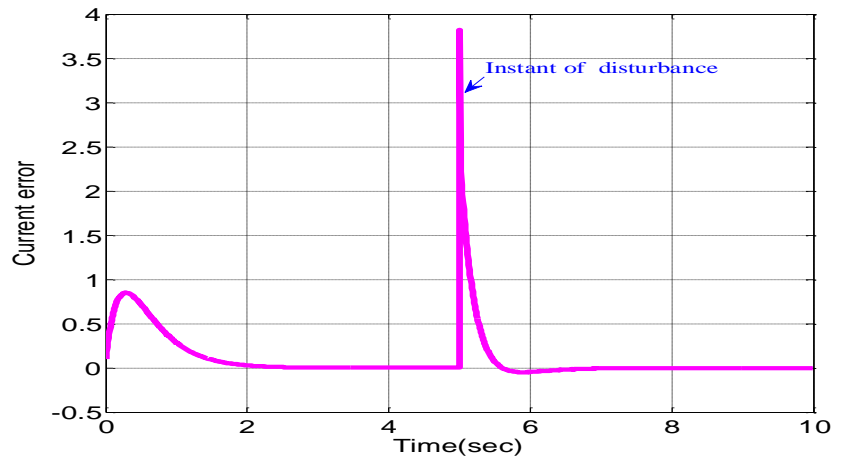

Figure 6(c)

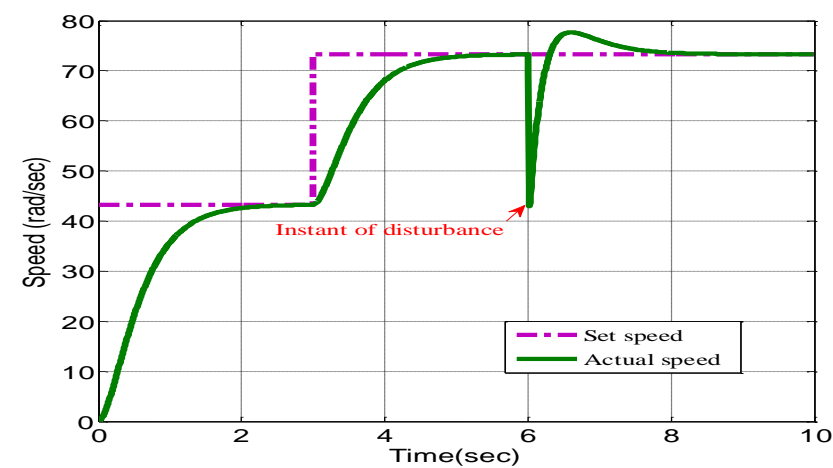

Figure 6(d)

Dynamic responses of speed, reference current command generated, current loop error and set-point tracking under inner loop disturbance with the proposed cascade control system are shown in figures $6(a)-6(d)$ respectively.

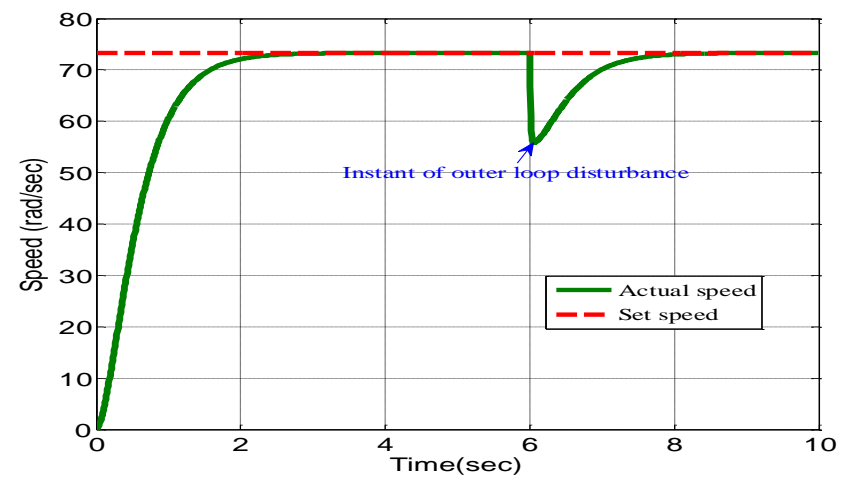

Figure 7(a)

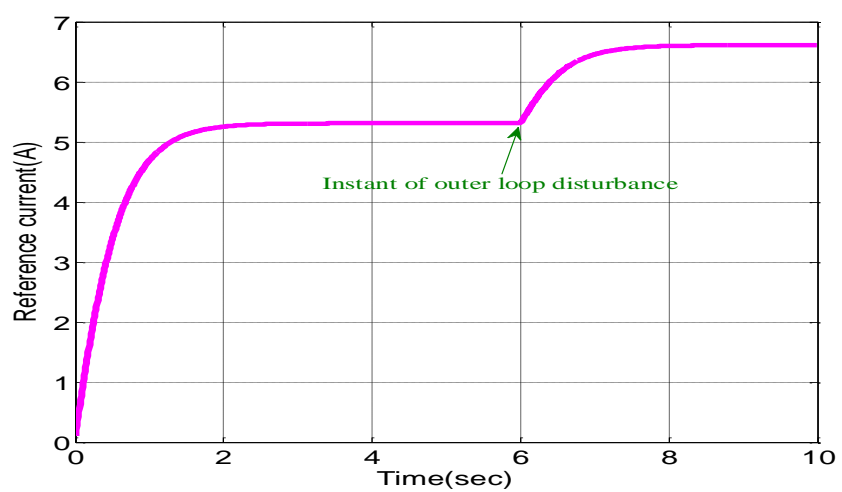

Figure 7(b) 


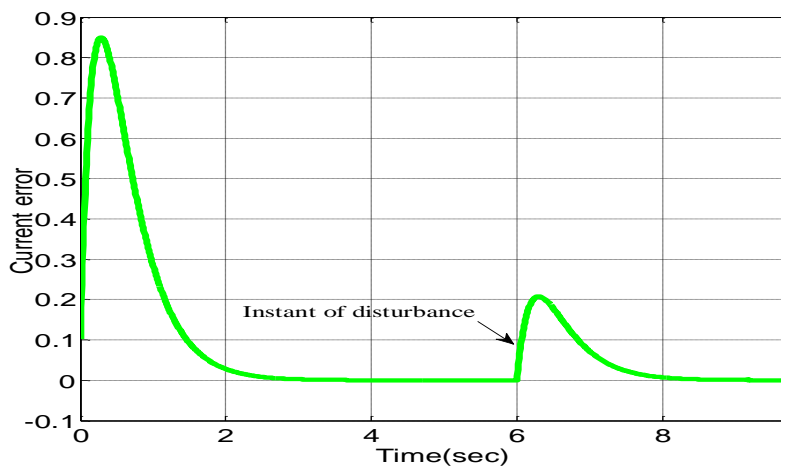

Figure 7(c)

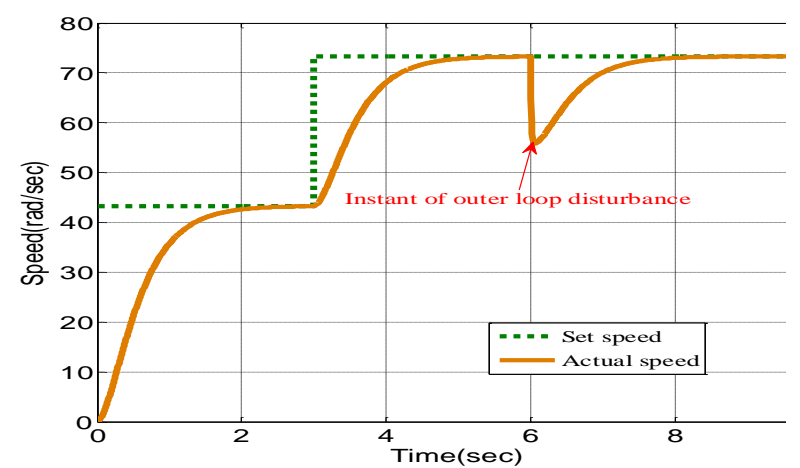

Figure 7(d)

Dynamic responses of speed, reference current command generated, current loop error and set-point tracking under outer loop disturbance with cascade control system are shown in figures $7(\mathrm{a})-7(\mathrm{~d})$ respectively.

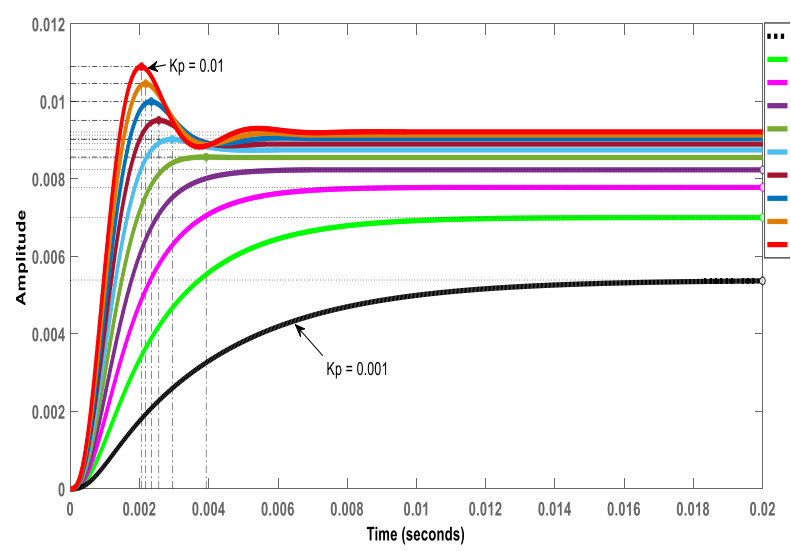

Figure 8(a)

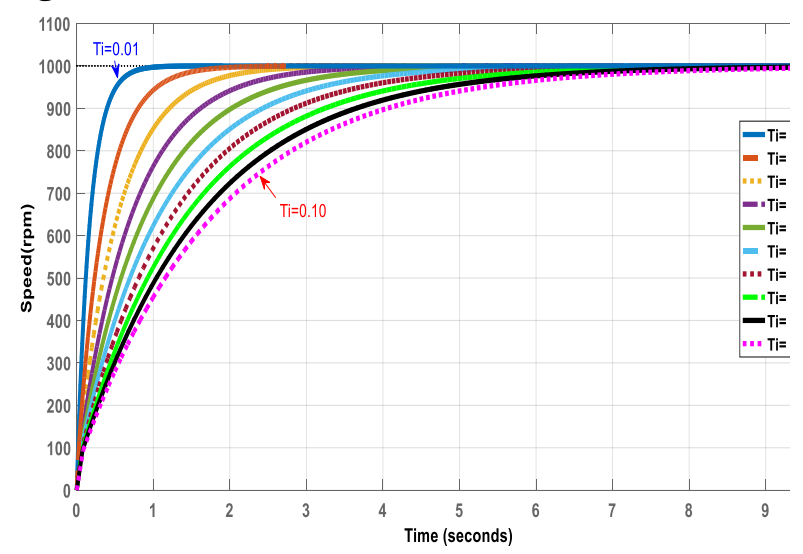

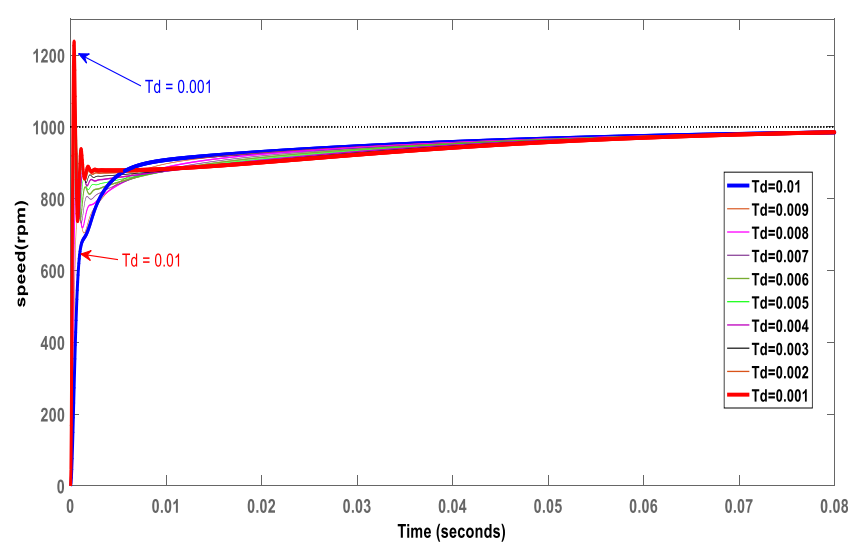

Figure 8(c)

Response with different values of $\mathrm{Kp}$, response with different values of $T_{i}$ and response with different values of $T_{d}$ are shown in figures $8(a)-8(c)$ respectively.

\section{Conclusion}

In this paper, cascaded control of brushless motor drive is proposed with MOMI tuning method to determine the parameters of PID controllers used in inner loop and outer loop. The motor drive system has been simulated using MATLAB/ SIMULINK. Several simulation tests were performed to investigate the robustness of the drive system and simulation results demonstrate the capability of performing under set-point changes, inner loop and outer loop disturbances. The dynamic responses with different values of controller parameters $K_{p}, T_{i}$, and $T_{d}$ were effective in their control actions. Therefore the proposed cascade control opens a new platform for the control of brushless motor drives.

\section{References}

[1] Manoj Kumar Merugumalla and Dr. N. Prema Kumar "FFA Based speed control of BLDC motor drive", International journal of (inpress). intelligent engineering informatics

[2] Manoj Kumar Merugumalla and Dr. N. Prema Kumar "Sensorless control of BLDC motor using bio-inspired optimization algorithm and classical methods of tuning PID

controller",Journal on Instrumentation and Control Engineering, Vol.5.No.1, pp.1623, 2017.

[3] Manoj Kumar Merugumalla and Dr. N. Prema Kumar "Optimized PID controller for BLDC motor using Nature-inspired Algorithms"International journal of Applied Engineering Research Vol.12, No.1, 2017.415-422, 2017.

[4] Sri Latha Eti and N. Prema Kumar 'closed loop control of BLDC motor drive using adaptive fuzzy tuned PI controller', journal of Engineering research and applications, 2014.

Figure 8(b) 
[5] Hua Ji , Zhiyong Li 'Modelling and simulation of control system for brushless DC motor',Int. J.of modeling identification and control, Vol. 7, No.4 pp. 346-350, 2009.

[6] K.J Astrom,C.C Hang,P.Persson and W.K Ho'Towards intelligent PID control', Automatica vol.28.no.1,pp.1-9,1992.

[7] Konstantinos G.Papodopoulos 'PID tuning using the magnitude optimum criterion', ebook springer, 2015.

[8] Damir vrancic, Youbin peng and Stanko strmcnik 'A new PID controller tuning method based on multiple integrations', pergamon, Control engineering practice vol.7,pp.623-633,1999

[9] Damir vrancic, Stanko strmcnik and Dani juricic 'A magnitude optimum multiple integration for filtered PID controller',Automatica vol.37,No.4,pp.1473-1479, 2001.

[10] Damir vrancic,Stanko strmcnik,Jus kocijan and P.B.de Moura Oliveira 'improving disturbance rejection of PID controllers by means of Magnitude optimum method '. ISA transactions, vol.49, pp. 47-56, 2009.

[11] Claudio Maffezzoni, Nicola Schiavoni, and Gianni Ferretti (1990) 'Robust Design of Cascade Control', IEEE control system magazine.pp.21-25, Jan 1990.

[12] Ahmed S. Abd Elhamid (2014) 'Cascade Control System of Direct Current Motor', World Applied Sciences Journal 18 (12): 1680 1688, 2012.

[13] R. Vilanova, O. Arrieta 'PID tuning for cascade control system design, Canadian Conference on Electrical and Computer Engineering,pp.1775-1778, June 2008.

[14] Antonio Visioli and Aurelio Piazzi 'An automatic tuning method for cascade control systems Proceedings of the 2006 IEEE International Conference on Control Applications Munich, Germany, October 4-6, 2006. 